\title{
STUDY OF PRECISION CAPABILITIES OF MOVABLE TWO-BLADE SKIVING BLOCK WITH INSERTS SHIFTED ON THE AXIS
}

\author{
Pavel Petrov ${ }^{1}$, Nely Georgieva ${ }^{2}$, Mihail Karshakov $^{1}$ \\ ${ }^{1}$ Ruse University, Studentska 8, Ruse, Bulgaria, \\ phone: +35982888474, e-mail: ppetrov@uni-ruse.bg, mkarshakov@uni-ruse.bg \\ ${ }^{2}$ Faculty of Technics and Technologies, Trakia University of Stara Zagora, \\ Graf Ignatiev 38, Yambol, Bulgaria, e-mail: nely.georgieva@trakia-uni.bg
}

\begin{abstract}
This article investigated the possibility of providing preliminarily elastic characteristic of movable two-blade skiving block with axially displaced inserts for achieving high accuracy, which does not depend on the diffusion of the allowance of machining

Keywords: skiving of hydraulic cylinders, movable two-blade block with axially displaced inserts.
\end{abstract}

\section{INTRODUCTION}

Tools for combined processing by cutting and surface plastic deformation (SPD) are widely used for mass processing of the openings of the hydraulic and pneumatic power cylinders [3]. Toward their working surfaces are laid down high requirements for quality in terms of accuracy of diametrically size and roughness. The roughness is achieved by deforming part of the combined instrument and the precision provided by the cutting part. It performs skiving most often with the help of two-blade block with oppositely arranged cutting inserts. During operation, the block is self-established in the radial direction as a result of the dynamic equilibrium between the radial cutting forces, guaranteed by its mobility in the direction of their effect.

\section{EXPOSE}

The movable two-blade block (MTB) is adjusted on the dimension in advance and dimension of the static adjusting $\left(L_{H}\right)$ does not correct during all work cycle. Therefore, by treating a batch details, the relation between tolerance of the opening diameter of the workpiece $\left(T D_{0}\right)$ and that of the treated surface $(T D)$ depends on the stability of the technological system, which in this case includes only the workpiece and MTB.

If the elastic deformation of the last mentioned is neglected the precision after skiving is so much higher, many as the higher is its strength in the radial direction.

There are structures of MTB in which the above conclusion is not valid. Their cutting inserts are displaced in the axial direction, i.e. their main cutting edges (homonymous points thereof) do not lie in a plane perpendicular to the axis of rotation. Displacement $(X)$ leads to increasing of the diameter of threated opening the dimension $\left(L_{H}\right)$ as a result of radial displacement $(\Delta)$ of MTB toward lagged insert and it is characterized by a limit value $\left(X_{2 p}\right)$, after which the displacement receives constant maximum value $[5,6]$. The reason for this is the self-establishment of the block to satisfy the dynamic equilibrium and the beneficial effect from this is the removal of the tool from the processed hole without scrapes on its surface.

It has been found theoretically that the axial displacement of the inserts $X \geq X_{z p}$ and nondeformable MTB Field of the dissipation of the workpiece can be reduced three times $[1,6]$. its precision capabilities is increased by increasing its amenability, whereby it is possible to IRTIIE Vol. 4, No. 3, 2016 ISSN 1314-8788 (print), ISSN 1314-8796 (online), doi: 10.15547/artte.2016.03.005 


\section{ART'TE $Y$}

Ipplied Researleches in Technics, Technologies and Bductition Journal of the Faculty of Technics and Technologies, Trakia University https://sites.google.com/a/trakia-uni.bg/artte/

determine an elastic feature in which the variance of allowance of machining for skiving will not impact on the obtained diameter [5,6]. Basis for this assertion is the deduced theoretical dependence

$$
T D=\frac{T D_{0}}{3}-\frac{4}{3}\left(\varepsilon_{\Gamma}-\varepsilon_{M}\right),
$$

where $\varepsilon_{\Gamma} и \varepsilon_{M}$ are respectively large and small elastic deformations of MTB obtained by maximum and minimum allowances of machining for skiving, generating relevant cutting forces $\left(F_{P}^{\max }\right.$ и $\left.F_{P}^{\min }\right)$.

It is obvious the existence of the theoretical possibility $T D=0$, if the difference between elastic deformation satisfies the condition

$$
\Delta \mathcal{E}=\varepsilon_{\Gamma}-\mathcal{E}_{M}=\frac{T D_{0}}{4}=\frac{\Delta Z}{2},
$$

where $\Delta Z$ is the unilateral increasing the allowances of machining.

This condition determines the type of the elastic characteristic of the body of MTB for the preparation of which is necessary to be known the cutting forces which provoke the above deformations. The connection between them can be seen from the dependencies:

$$
\varepsilon_{M}=\frac{F_{P}^{\min } . \Delta \varepsilon}{\Delta F_{P}} ; \varepsilon_{\Gamma}=\frac{F_{P}^{\max } . \Delta \varepsilon}{\Delta F_{P}},
$$

Methodology for determining the elastic characteristics of the MTB comprises the following steps:

$>$ The field of dispersion of the diameter of the workpiece (by measuring of the batch cylinders before the combined treatment) is determined

$$
T D_{0}=D_{0}^{\Gamma}-D_{0}^{Д}, m m \text {. }
$$

where $D_{0}^{\Gamma}$ and $D_{0}^{\not}$ are respectively upper and lower limit dimensions of the opening of the workpiece.

$>$ The minimum and maximum depths of cut depending on the variation of allowances of machining are calculated

$$
\begin{aligned}
& a_{P}^{\min }=\frac{D^{Д}-D_{0}^{\Gamma}}{4}, \mathrm{~mm} \\
& a_{P}^{\max }=\frac{D^{\Gamma}-D_{0}^{Д}}{4}, \mathrm{~mm}
\end{aligned}
$$

where $D^{\Gamma}$ and $D^{\not}$ are respectively upper and lower limit dimensions of the opening after machining.

$>$ The radial cutting forces corresponding to the minimum and maximum depths of cut are calculated:

$$
\begin{aligned}
& F_{P}^{\min }=549+3970 \cdot a_{P}^{\min }, N \\
& F_{P}^{\max }=549+3970 \cdot a_{P}^{\max }, N
\end{aligned}
$$

Used dependencies are the result of a single factor experiment. The necessary difference between the maximum $\left(\varepsilon_{\Gamma}\right)$ and minimum $\left(\varepsilon_{M}\right)$ elastic deformations corresponding to $F_{P}^{\max }$ and $F_{P}^{\text {min }}$ is determined and under condition (1) it must be

$$
\Delta \mathcal{E}=\frac{T D_{0}}{4}
$$

IRTIIE Vol. 4, No. 3, 2016 ISSN 1314-8788 (print), ISSN 1314-8796 (online), doi: 10.15547/artte.2016.03.005 


\section{IRTITE}

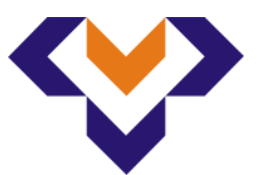

Ipplied Resseirl'hes in Teednicis, Technologies and Eductation

Journal of the Faculty of Technics and Technologies, Trakia University https://sites.google.com/a/trakia-uni.bg/artte/

D The desired elastic characteristic of MTB $F_{P}=f(\mathcal{E})$ is determined (may be presented graphically) as a straight line equation $F_{P}=k \mathcal{E}$, in which

$$
k=\operatorname{tg} \frac{\Delta F_{P} \cdot M_{F}}{\Delta \mathcal{E} \cdot M_{\varepsilon}},
$$

where $\Delta F_{P}=F_{P}^{\max }-F_{P}^{\min }$;

$\mathrm{M}_{\mathrm{F}} и \mathrm{M}_{\mathcal{E}}$ - the scale of the introduction of the corresponding values of $F_{P}$ and $\varepsilon$ on the axes of Cartesian coordinate system (figure 1).

> After preparation of MTB a test is done to determine whether its structure has stability which satisfying the built elastic characteristic. For this purpose MTB is loaded in the plane of action of the radial cutting forces with any force $F_{P}$ within the range $F_{P}^{\min } \div F_{P}^{\max }$, that, the measured deformation $\mathcal{E}_{P}$ should have size magnitude $\varepsilon_{P} M_{\varepsilon}=\frac{F_{P} M_{F}}{k}$ or is determined by equations (3). If this condition is not satisfied, actions to alter the stability of MTB are made to its implementation.

$>$ The size of static adjustment $\mathrm{L}_{H}$ is determined (the distance between the corner of the cutting inserts in a plane perpendicular to the axis of rotation of the workpiece) by the relation:

$$
L_{H}=\frac{3 D^{\Gamma}+4 \varepsilon_{\Gamma}+D_{0}^{\not}}{4}
$$

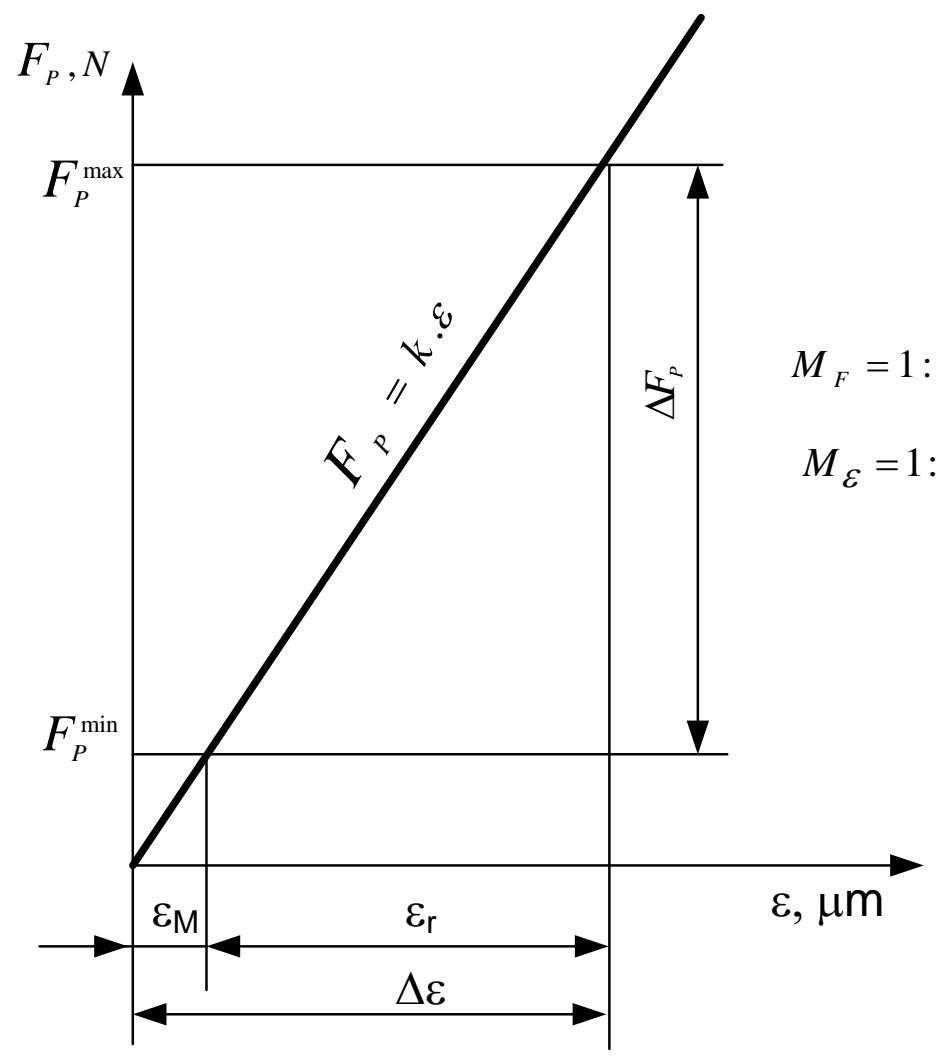

Figure 1. Regulated elastic characteristic of MTB

> Cutting conditions of the SPD is selected.

IRTITE Vol. 4, No. 3, 2016 ISSN 1314-8788 (print), ISSN 1314-8796 (online), doi: 10.15547/artte.2016.03.005 


\section{IRITIE \\ $y^{2}$ \\ Ipplied Researthes in Technics, Technologies and Bduration \\ Journal of the Faculty of Technics and Technologies, Trakia University https://sites.google.com/a/trakia-uni.bg/artte/}

\section{METHODOLOGY FOR EXPERIMENTAL STUDY}

\subsection{Purpose of the study}

Purpose of this study is the established theoretical dependence between the stability and accuracy of MTB after skiving openings with axial displacement of the cutting inserts, equal to or greater than the limit to be verified.

\subsection{Test specimens}

Test specimens are made in a manner consistent with the implementation of the production method for determining the stability of the technological system [4]. In this case it is used to determine the variance of the diameter after skiving with MTB with regulated stability in a predetermined dispersion of the opening diameter of the workpiece. Three identical specimens were prepared. Its design (shown in Figure 2) is consistent with the need to be established on the machine.

After the regulation of the cutting and deforming parts the samples are processed by single pass in direction indicated by $f$, whereby the allowance of machining of step 1 is insignificant $(0,05-0,1 \mathrm{~mm})$, and the steps 2 and 3 are respectively with minimum and maximum allowance, which is the result of the actual field of dissipation of the diameters of the batch workpieces. Obtained diameters of steps 2 and 3 after the combined treatment are measured by a bore gauge with graduation $0,001 \mathrm{~mm}$.

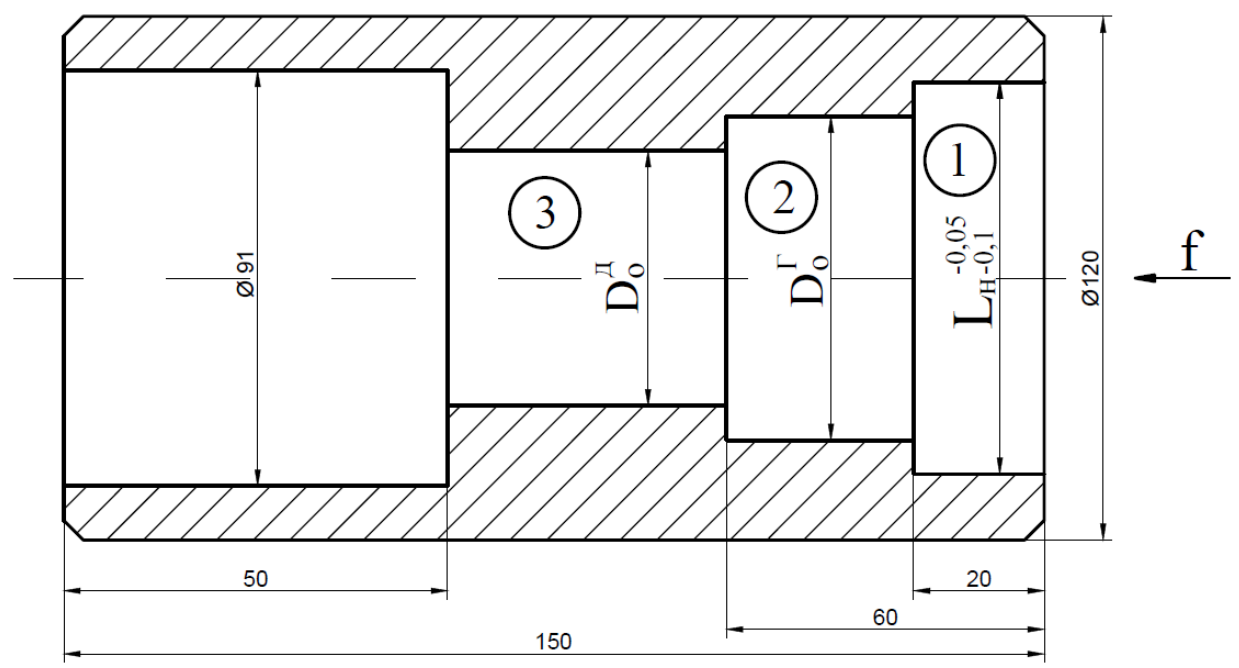

Figure 2. Test specimen for studying the impact of the stability of the MTB on accuracy of skiving with axially displaced inserts at a distance $X_{0} \geq X_{r p}$

Cutting part of the Instrument for combined processing contain MTB with prismatic crosssection (Figure 3and integrated elastic element with regulated characteristics defined by the above procedure. The cutting inserts have the following geometry: $\alpha_{0}=10^{\circ} ; \gamma_{0}=0^{\circ}$; $\lambda_{s}=0^{o} ; r_{e}=0,2 \mathrm{~mm} ; \kappa_{r}=7^{o} ; \kappa_{r}^{\prime}=1^{o}$.

The deforming part of the instrument is adjusted for work with tightness $0,1 \mathrm{~mm}$ toward the expected dimension after cutting part. All three steps of the test specimens are machined, relying on the function of vibration damping of the deforming part. The allowable dispersion

IRTTE Vol. 4, No. 3, 2016 ISSN 1314-8788 (print), ISSN 1314-8796 (online), doi: 10.15547/artte.2016.03.005 


\section{IRTITIE

of steps diameters 2 and 3 of the individual specimens before the test is $0,2 \mathrm{~mm}$. The experiments were carried out without coolant and for ejecting the chips before the instrument is used compressed air.
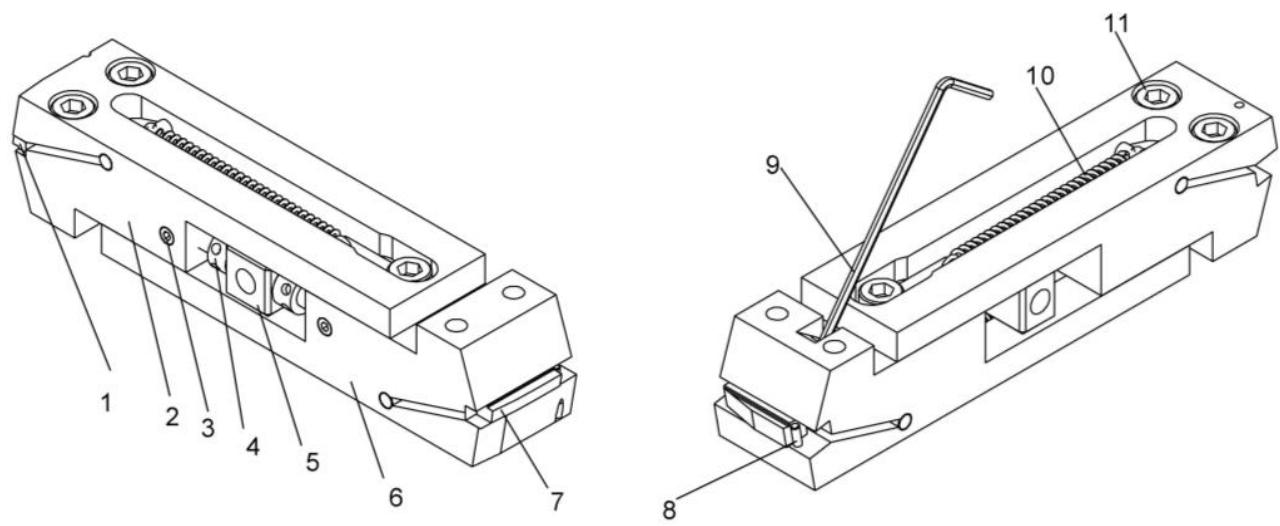

Figure 3. Movable two-blade block

\subsection{Terms of carrying out the examinations and obtained results}

The conditions for carrying out the examinations cover three groups of parameters dimensional, power and regime. Dimensional parameters include tolerances and limit values of the hole diameter the before $\left(D=90 H 8=90^{+0,054}\right)$ and after $\left(D_{0}=89^{+0,5}\right)$ combined treatment. The power parameters are obtained through the methodology, exposed above and are determined the regulated stability of MTB. Regime parameters include elements of cutting condition $\left(a_{P}, f, V_{C}\right)$ and of SPD (tightness $-C$ ).

All parameters and results of the tests are shown in Table1.

Table 1. Conditions for carrying out and results of the examinations

\begin{tabular}{|c|c|c|c|c|c|}
\hline \multicolumn{6}{|c|}{ Conditions for carrying out the examinations } \\
\hline \multicolumn{2}{|c|}{ Dimensional parameters } & \multicolumn{2}{|c|}{ Power parameters } & \multicolumn{2}{|c|}{ Regime parameters } \\
\hline \multicolumn{2}{|c|}{$D^{Д}=90,00 \mathrm{~mm}$} & \multicolumn{2}{|c|}{$F_{P}^{\min }=1045 N$} & \multicolumn{2}{|c|}{$a_{P}^{\min }=0,125 \mathrm{~mm}$} \\
\hline \multicolumn{2}{|c|}{$D^{\Gamma}=90,054 \mathrm{~mm}$} & \multicolumn{2}{|c|}{$F_{P}^{\max }=1580 N$} & \multicolumn{2}{|c|}{$a_{P}^{\max }=0,260 \mathrm{~mm}$} \\
\hline \multicolumn{2}{|c|}{$D_{0}^{\text {म }}=89,00 \mathrm{~mm}$} & \multicolumn{2}{|c|}{$\varepsilon_{M}=244 \mu m$} & \multicolumn{2}{|c|}{$f=1,5 \mathrm{~mm} / \mathrm{rev}$} \\
\hline \multicolumn{2}{|c|}{$D_{0}^{\Gamma}=89,50 \mathrm{~mm}$} & \multicolumn{2}{|c|}{$\mathcal{E}_{\Gamma}=369 \mu m$} & \multicolumn{2}{|c|}{$V_{C}=50,8 \mathrm{~m} / \mathrm{min}$} \\
\hline \multicolumn{2}{|c|}{$T D=0,054 \mathrm{~mm}$} & \multicolumn{2}{|c|}{$\Delta F_{P}=535 N$} & \multicolumn{2}{|c|}{$C=0,1 \mathrm{~mm}$} \\
\hline \multicolumn{2}{|c|}{$T D_{0}=0,5 \mathrm{~mm}$} & \multicolumn{2}{|c|}{$\Delta \varepsilon=125 \mu m$} & \multicolumn{2}{|c|}{$L_{H}=90,16 \mathrm{~mm}$} \\
\hline \multicolumn{6}{|c|}{ Results of the examinations } \\
\hline \multirow{2}{*}{$\begin{array}{c}\text { Test } \\
\text { specimen } \\
\text { № }\end{array}$} & \multicolumn{2}{|c|}{$\begin{array}{c}\text { Diameters after combined } \\
\text { treatment, } \mathrm{mm}\end{array}$} & \multicolumn{2}{|c|}{ Difference between 2 and 3} & \multirow{2}{*}{$\begin{array}{l}\text { Roughness } \\
\text { Ra, } \mu \mathrm{m}\end{array}$} \\
\hline & step 2 & step 3 & $\mathrm{~mm}$ & $\%$ to TD & \\
\hline 1 & 90,063 & 90,070 & 0,007 & 13 & 0,28 \\
\hline 2 & 90,057 & 90,067 & 0,010 & 18 & 0,33 \\
\hline 3 & 90,049 & 90,055 & 0,006 & 11 & 0,24 \\
\hline
\end{tabular}




\section{ARTTIE $Y$}

Ipplied Resseirlohes in Technics, Technologies and Bductation

Journal of the Faculty of Technics and Technologies, Trakia University https://sites.google.com/a/trakia-uni.bg/artte/

\section{ANALYSIS OF RESULTS}

The test results show a relatively high degree of overlapping of theoretically justified expectations of the capabilities of the PSUR with axially displaced cutting inserts to exhibit insensitivity to the dissipation of the machining allowance, when the elastic characteristic which expressing its stability is obeyed a certain dependence between radial forces and deformations, i.e. is regulated. Reason for such an opinion is little difference between the diameters of steps $\mathbf{2}$ and $\mathbf{3}$, which indicates reduction of the tolerance of the workpiece from 50 to 80 times. Besides, the diameters of the steps are about the upper limit or a little exceed it. One of the reason for this could be the expected enlargement of the opening in result of SPD, which generally does not exceed $0,01-0,02 \mathrm{~mm}$.

The fixed difference between the steps of the specimens ranges from 11 to $18 \%$, which is within the acceptable error in carrying out experimental studies of processing by cutting.

The measured roughness entirely satisfies the requirements of the cylinder opening surfaces.

\section{CONCLUSIONS}

- With known (allowable) fields of the dispersing of the diameters of the openings before and after skiving with MTB with axial displacement of the cutting inserts $X_{0} \geq X_{c p}$ and reliable correlations for determining the cutting forces, it is not difficult to create a design feature so that the body of MTB to possess regulated elastic characteristics (condition 1) for achieving high accuracy with minimal depending on the fluctuation of the allowance of machining for skiving.

- Using of the MTB with regulated elastic characteristic of its body required in the construction of the tool for combined processing to exist a device to change the dimension of the static setting at the beginning and end of stroke which should be larger than the upper limit of the diameter of the processed opening and it is not possible removal of the tool without scratching the treated surface.

\section{REFERENCES}

[1] Grigorov V., N. Georgieva, M. Karshakov, D. Dimimtrov. Exploring the Dimensions formation in turning shafts with movable two-blade block, Journal Mechanical engineering and machine knowledge, Vol. 3, No.17, 2012.

[2] Kostadinov V. Study the influence of the axial displacement of the blades in combined processing by movable cutting block. Scientific papers of the University "Angel Kanchev" Rousse, Vol. XXXII, 1989.

[3] Karshakov M. Theoretical and experimental development on combined treatment of deep holes by cutting and surface plastic deformation, Habilitation thesis, Rousse, 2009.

[4] Paterinski P. Manufacturing Technologies, Sofia, Technics, 1973, 251 p.

[5] Petrov P., N. Georgieva, M. Karshakov. Influence the stability of movable cutting block on the accuracy at turning holes, Proceedings "XXIII International Scientific and Technical Conference“, ADP 2014., Sozopol - June 2014, pp. 360-365.

[6] Petrov P. Combined treatment of deep holes by cutting and surface plastic deformation. PhD Thesis, Rousse, September, 2015. 